\title{
EFEKTIVITAS MODEL PEMBELAJARAN KOOPERATIF TIPE PAIR CHECK TERHADAP HASIL BELAJAR MATEMATIKA SISWA KELAS IX SMP NEGERI 17 BATAM
}

\author{
Sumartono Ibrahim Teibang, Asmaul Husna* \\ Program Studi Pendidikan Matematika, Fakultas Keguruan dan Ilmu Pendidikan \\ Universitas Riau Kepulauan, Batam, Kepulauan Riau-Indonesia \\ *e-mail :asmaul_uul25@yahoo.com
}

\begin{abstract}
Abstrak. Penelitian ini bertujuan untuk mengetahui: (1) Efektivitas penerapan model pembelajaran kooperatif tipe Pair Check terhadap hasil belajar matematika (2) Efektivitas model pembelajaran konvensional terhadap hasil belajar matematika (3) Perbedaan keefektifan model pembelajaran kooperatif tipe Pair Check dengan model pembelajaran konvensional terhadap hasil belajar matematika. Jenis penelitian ini eksperimen semu dengan desain Posttest Only Control Group Design. Populasi penelitian ini seluruh siswa SMP Negeri 17 Batam kelas IX tahun pelajaran 2018/2019 yang berjumlah 158 siswa. Pengambilan sampel menggunakan Cluster Random Sampling. Sampel penelitian adalah $\mathrm{IX}_{\mathrm{D}}$ sebagai kelas eksperimen menerapkan model pembelajaran kooperatif tipe Pair Check sebanyak 32 siswa dan $\mathrm{IX}_{\mathrm{A}}$ sebagai kelas kontrol menerapkan model pembelajaran konvensional sebanyak 32 siswa. Instrumen penelitian berupa tes uraian sebanyak 5 soal. Yang telah melewati uji validitas dan realibilitas dengan koefisien reliabilitas instrument sebesar 0,85 . Analisis data yang digunakan adalah uji t, hasil analisis data menunjukkan bahwa skor rata-rata tes hasil belajar matematika kelas eksperimen adalah 79,63 dan skor rata-rata kelas kontrol adalah 71,56. Hasil penelitian menunjukkan (1) Model pembelajaran kooperatif tipe Pair Check efektif terhadap hasil belajar matematika dengan nilai signifikansi adalah 0,023 (2) Model pembelajaran konvensional tidak efektif terhadap hasil belajar matematika dengan nilai signifikansi adalah 0,105 (3) Terdapat perbedaan keefektifan model pembelajaran kooperatif tipe Pair Check dengan model pembelajaran konvensional terhadap hasil belajar matematikadengan nilai signifikansi adalah 0,039.
\end{abstract}

Kata Kunci: Model Pembelajaran Kooperatif Tipe Pair Check, Model Pembelajaran Konvensional dan Hasil Belajar Matematika.

\begin{abstract}
This research aims to find out: (1) Effectiveness of Pair Check model of cooperative learning model toward mathematics learning result (2) Effectiveness of conventional learning model on mathematics learning outcomes (3) Differences effectiveness of cooperative learning model type Pair Check with The conventional learning model of learning outcomes. This type of experimental research was false with Posttest Only Control Group Design. The population of study was all students off SMP Negeri 17 Batam class IX 2018/2019 academic year with 158 students. Sampling was using Cluster Random Sampling. The sample of research was $\mathrm{IX}_{\mathrm{D}}$ as experiment class applying cooperative learning model type Pair Check using Power Point with 32 students and $\mathrm{IX}_{\mathrm{A}}$ as control class applying conventional learning model with 32 students. The research instrument was description test with 5 questions. The reliability instrument coefficient was 0,85 . The results of data analysis showed that the average score of the experimental class learning test was 79,63 and the average score of the control class was 71,56. The results of the research showed: (1) Pair Check type cooperative learning model effective toward mathematics learning result with significance value is 0,023 (2) Ineffective conventional learning model toward mathematics learning result with significance value is 0,105 (3) There is the difference between learning model type Pair Check and conventional with 0,039 significance.

Keywords: Cooperative Learning Model Type Pair Check, Conventional Learning Model and Mathematics Learning Outcomes.
\end{abstract}




\section{Pendahuluan}

Pendidikan memiliki peran penting dalam upaya menciptakan Sumber Daya Manusia (SDM) yang berkualitas dan dapat bersaing di tingkat global.Melihat begitu pentingnya pendidikan dalam pembentukan SDM, maka peningkatan mutu pendidikan merupakan hal yang wajib dilakukan secara berkesinambungan agar terciptanya SDM yang berkualitas. Upaya peningkatan mutu pendidikan berhubungan erat dengan proses pembelajaran. Menurut Sukarsa \& Arini, (2014: 2) "proses pembelajaran lebih menekankan kepada siswa untuk memiliki potensi belajar aktif dalam pencarian dan pengembangan pengetahuan". Salah satu proses pembelajaran yang menekankan pada siswa untuk memiliki potensi aktif dalam pencarian adalah matematika. Matematika merupakan salah satu mata pelajaran yang diwajibkan disetiap jenjang sekolah mulai dari SD sampai SMA. Salah satu karakteristik matematika adalah sifatnya yang menekankan pada proses deduktif yang memerlukan penalaran logis, diawali dengan proses induktif (Hendiana\&Soemarmo, 2014: 3).

Adapun tujuan penting dari mempelajari matematika adalah menghasilkan siswa yang mampu menyelesaikan segala permasalahan yang dihadapi, baik yang datang dari guru, maupun dari kehidupan sehari-hari yang dilewatinya, serta dari berbagai sumber lainnya dengan cara yang paling baik, cepat dan tepat. Hal ini membuktikan bahwa matematika merupakan salah satu dari sekian banyak mata pelajaran yang perlu untuk dikuasi oleh seorang siswa. Tentu dalam proses pengajaran matematika tidak akan semulus yang diinginkan oleh seorang tenaga pengajar, pasti ada hambatan yang membuat hasil dari suatu pembelajaran matematika dinilai kurang bisa optimal.

Berdasarkan hasil observasi yang telah peneliti lakukan di SMP Negeri 17 Batam pada kelas IX, menunjukkan bahwa proses pembelajaran yang berlangsung masih mengandalkan guru sebagai pemberi sumber belajar. Penerapan model pembelajaran konvensional membuat siswa merasa jenuh karena kurangnya peran serta siswa pada proses pembelajaran yang berlangsung. Selain itu, selama proses kegiatan pembelajaran siswa cenderung hanya memahami bagaimana menyelesaikan suatu permasalahan dengan mengaplikasikan konsepkonsep pembelajaran yang diberikan, tanpa memahami bagaimana dan kenapa konsep-konsep tersebut ada.

Sedangkan, berdasarkan hasil wawancara dengan siswa kelas IXA dan IXB SMP Negeri 17 Batam diperoleh informasi siswa beranggapan bahwa matematika itu menakutkan untuk dipelajari dan masih mengeluh kesulitan untuk menyelesaikan masalah dalam pelajaran matematika. Faktor lainnya adalah kurang tepatnya penggunaan model pembelajaran. Pemilihan model pembelajaran konvensional yang digunakan kurang sesuai dengan karakteristik siswa, guru menjelaskan materi di depan kelas, sedangkan siswa hanya fokus mendengar penjelasan guru sehingga menimbulkan kejenuhan, monoton dan siswa yang cenderung pasif pada saat proses pembelajaran berlangsung. Permasalahan lain yang terlihat adalah hasil belajar siswa yang masih rendah, hal ini terlihat dari persentase ketercapaian KKM nilai ujian semester ganjil siswa kelas IX di SMP Negeri 17 Batam yang masih di bawah persentase yang diharapkan. Berikut ini adalah hasil belajar matematika kelas IX SMP Negeri 17 Batam. 
Tabel 1. Nilai Matematika Kelas IX Semester Ganjil TP.2018/2019

\begin{tabular}{cccccc}
\hline \multirow{2}{*}{ Kelas } & Total Siswa & \multicolumn{2}{c}{ Tuntas $(>75)$} & \multicolumn{2}{c}{ Tidak Tuntas $(<75)$} \\
\cline { 3 - 6 } & & Jumlah Siswa & Persentase & Jumlah Siswa & Persentase \\
\hline IX A & 32 & 11 & $34.38 \%$ & 21 & $65,62 \%$ \\
IX B & 32 & 13 & $40,63 \%$ & 19 & $59,37 \%$ \\
IX C & 31 & 16 & $51,61 \%$ & 14 & $48,39 \%$ \\
IX D & 32 & 15 & $46,88 \%$ & 17 & $53,12 \%$ \\
IX E & 31 & 13 & $41,94 \%$ & 18 & $58,06 \%$ \\
\hline
\end{tabular}

Berdasarkan Tabel 1 di atas terlihat bahwa hasil belajar matematika siswa masih tergolong rendah karena persentase nilai 48,39\% - 65,62\% masih belum tuntas, sedangkan hanya $34,38 \%$ - 51,61\% siswa yang tuntas. Masih banyak siswa yang belum mencapai KKM dikarenakan masih banyak siswa yang mengalami kesulitan dalam menyelesaikan soal matematika.Untuk mengantisipasi masalah tersebut, maka perlu dicarikan suatu model pembelajaran yang tepat sehingga dapat meningkatkan hasil belajar matematika siswa. Salah satu model pembelajaran yang dirasa dapat digunakan dalam meningkatkan hasil belajar matematika siswa adalah model pembelajaran kooperatif tipe Pair Check. Menurut Kurniasih \& Sani (2015: 111), Hadi \& Kasum (2015:60), Lestari \& Linuwih (2012:191) menyatakan bahwa "model pembelajaran Pair Check adalah proses belajar yang mengedepankan kerja sama kelompok yang harus memiliki kemandirian, kemampuan menyelesaikan persoalan, melatih tanggung jawab sosial siswa, dan kerja sama”. Dengan model pembelajaran Pair Check pembelajaran akan lebih terpusat kepada siswa (student center) karena siswa dituntut untuk saling berbagi pengetahuan tentang materi yang dibahas sehingga terjadi saling tukar pendapat antar siswa dan juga melatih siswa aktif dalam proses pembelajaran. Sesuai dengan pendapat Huda (2014:211), Istarani \& Ridwan (2015:165) siswa tidak sungkan bertanya kepada temannya yang lebih mengerti dan setiap siswa juga dituntut untuk memiliki tanggung jawab terhadap tugasnya masing-masing hal ini diyakini akan meningkatkan kemampuan kognitif siswa yang berdampak pada hasil belajar yang diperoleh siswa akan lebih memuaskan.

\section{Metode Penelitian}

Jenis penelitian ini adalah penelitian eksperimen semu (quasi experiment), desain penelitian yang digunakan dalam penelitian ini adalah Posttest Only Control Group Design. Adapun populasi pada penelitian ini adalah seluruh siswa kelas IX di SMP Negeri 17 Batam Tahun Pelajaran 2018/2019 yang berjumlah 158 siswa. Teknik pengambilan sampel yang digunakan dalam penelitian ini adalah dengan teknik Cluster Random Sampling. Adapun prosedur Cluster Random Sampling pada penelitian ini adalah dengan cara mencabut undian berbentuk gulungan kertas. Setiap satu gulungan kertas mewakili satu kelas IX yang dilakukan oleh guru pelajaran matematika. 
Instrumen adalah alat untuk mengukurkan informasi atau melakukan pengukuran.Menurut Siregar (dalam Hendiana \& Soemarmo, 2014: 73) mengemukakan bahwa instrumen penelitian adalah suatu alat yang dapat digunakan untuk memperoleh, mengolah, dan menginterpretasikan informasi. Instrumen dalam penelitian ini menggunakan test. Jenis tes ini adalah tes uraian dalam bentuk soal essai. Tes uraian terdiri dari 5 soal dengan materi persamaan kuadrat. Pemberian tes uraian dilaksanakan setelah kedua kelas sampel diberikan treatmen yaitu menggunakan Model Pembelajaran Kooperatif Tipe Pair Check pada sampel pertama sedangkan metode konvensional sampel kedua. Adapun kisi-kisi soal yang digunakan sebagai instrumen penelitian dapat dilihat sebagai berikut:

Tabel 2. Kisi-kisi Instrumen Hasil Belajar Matematika

\begin{tabular}{|c|c|c|}
\hline Kompetensi Dasar & $\begin{array}{c}\text { Indikator Pencapaian } \\
\text { Kompetensi }\end{array}$ & Nomor Butir Soal \\
\hline \multirow[t]{3}{*}{$\begin{array}{l}\text { Menjelaskan persamaan } \\
\text { kuadrat dan } \\
\text { karakteristiknya } \\
\text { berdasarkan akar-akar } \\
\text { serta penyelesaiaanya }\end{array}$} & $\begin{array}{l}\text { Menganalisis faktor-faktor } \\
\text { bentuk aljabar dalam persamaan } \\
\text { kuadrat dan cara } \\
\text { menentukan akar-akar } \\
\text { persamaan kuadrat. }\end{array}$ & 1 \\
\hline & $\begin{array}{l}\text { Menjelaskan persamaan kuadrat } \\
\text { dan karakteristiknya serta cara } \\
\text { penyelesaiannya. }\end{array}$ & 2,3 \\
\hline & $\begin{array}{l}\text { Menyelesaikan masalah yang } \\
\text { berkaitan dengan persamaan } \\
\text { kuadrat }\end{array}$ & 4,5 \\
\hline
\end{tabular}

Instrumen yang digunakan dalam penelitian ini adalah instrumen tes yang berbentuk soal uraian terdiri dari 5 butir soal. Tes merupakan suatu teknik atau cara yang digunakan dalam rangka melaksanakan kegiatan pengukuran, yang didalamnya terdapat berbagai pertanyaan, pernyataan atau serangkaian tugas yang harus dikerjakan atau dijawab oleh siswa untuk mengukur aspek perilaku siswa (Lubis, 2013). Sebelum tes diberikan kepada kelas sampel, terlebih dahulu instrumen tes tersebut di ujicobakan ke kelas yang berada di luar sampel yaitu kelas $\mathrm{IX}_{\mathrm{C}}$ SMPN 17 Batam. Analisis hasil data uji coba dilakukan dengan validitas konstruk menggunakan rumus korelasi Product Moment, kemudian dilakukan analisis butir soal berupa indeks kesukaran dan daya pembeda. Selanjutnya dilanjutkan uji reliabititas untuk melihat ketepatan butir soal dengan menggunakan rumus Alpha Cronbach. Setelah dilakukan uji validitas, indeks kesukaran, daya pembeda dan reliabilitas maka instrumen sudah layak untuk digunakan. Sesuai dengan uji validitas dari 10 butir soal yang di uji cobakan terdapat 5 soal valid dan 5 soal yang tidak valid. Untuk indeks kesukaran dari 5 butir soal tersebut 1 soal kategori mudah, 3 soal kategori sedang dan 1 soal kategori sukar. Sedangkan daya pembeda diperoleh bahwa pada 5 butir soal daya pembeda kategori baik. Untuk reliabel butir soal tersebut hasil reliabelnya adalah 0,85 . Hal ini dapat disimpulkan $r>$ $0,6(0,85>0,6)$ maka soal tersebut reliabel.

Uji prasyarat analisis dilakukan sebelum melakukan uji hipotesis yaitu uji normalitas dan uji homogenitas. Uji normalitas menggunkan uji Kolmogorov Smirnov. Selanjutnya 
dilakukan pengujian homogenitas, Uji homogenitas dilakukan untuk mengetahui apakah variansi data dari sampel yang dianalisis homogen atau tidak. Perhitungan homogenitas dengan uji homogenitas variansi yang dilakukan dengan menggunakan bantuan program SPSS statistik 20. Setelah prasyarat analisis data maka dilakukan uji hipotesis, untuk hipotesis satu dan dua menggunakan uji One Sample T-Test, dengan kriteria Jika (sig.) > 0,05 maka $\mathrm{H}_{0}$ diterima dan Jika (sig.) $\leq 0,05$ maka $\mathrm{H}_{0}$ ditolak. Selanjutnya untuk pengujian hipotesis tiga menggunakan Independent Sample T-Test, dengan kriteria Jika (sig.) > 0,05 maka $\mathrm{H}_{0}$ diterima dan Jika (sig.) $\leq 0,05$ maka $\mathrm{H}_{0}$ ditolak.

\section{Hasil Penelitian dan Pembahasan}

Penelitian ini dilakukan untuk melihat efektivitas model pembelajaran Pair Check terhadap hasil belajar matematika siswa kelas IX SMP Negeri 17 Batam TP. 2018/2019. Agar dapat melihat efektivitas model pembelajaran Pair Check terhadap hasil belajar matematika, maka akan dilakukan perbandingan penerapan model pembelajaran Pair Check dan penerapan model pembelajaran konvensional. Kedua model pembelajaran akan diterapkan pada masingmasing kelas yaitu model pembelajaran Pair Check pada kelas eksperimen dan model pembelajaran konvensional pada kelas kontrol, peneliti akan melihat keefektifan masingmasing model pembelajaran Pair Check dan model pembelajaran konvensional. Berikut hasil posttest yang akan dilakukan analisis data pada hipotesis:

Tabel 3. Rangkuman Data Posttest Kelas Sampel

\begin{tabular}{lclc}
\hline \multicolumn{4}{c}{ Data Posttest Kelas Sampel } \\
\hline & Eksperimen $\left(\mathbf{I X}_{\mathbf{D}}\right)$ & \multicolumn{1}{c}{ Kontrol $\left(\mathbf{I X}_{\mathbf{A}}\right)$} \\
\hline Nilai Max & 100 & Nilai Max & 100 \\
Nilai Min & 58 & Nilai Min & 30 \\
Skor Ideal & 100 & Skor Ideal & 100 \\
Rata-rata & 79,63 & Rata-rata & 71,56 \\
Standar deviasi & 12,61 & Standar deviasi & 15,20 \\
Varians & 159,08 & Varians & 231,16 \\
\hline
\end{tabular}

Uji normalitas digunakan untuk mengetahui apakah populasi data berdistribusi normal atau tidak. Dalam penelitian ini, uji normalitas yang digunakan adalah Kolmogorov smirnov dengan bantuan SPSS 20 for Windows. Data yang diolah adalah hasil belajar siswa yang diperoleh setelah dilakukan tes dengan kaidah pengujiannya yaitu: jika probabilitas $(\mathrm{Sig}) \geq$ 0,05, maka data berdistribusi normal sedangkan jika probabilitas $(\mathrm{Sig})<0,05$, maka data tidak berdistribusi normal. 
Tabel 3.Rangkuman Uji Normalitas Data Posttest

\begin{tabular}{rcc}
\hline & \multicolumn{2}{c}{ Uji Normalitas Data Post Test } \\
\hline & Eksperimen $\left(\mathrm{IX}_{\mathrm{D}}\right)$ & Kontrol $\left(\mathrm{IX}_{\mathrm{A}}\right)$ \\
\hline Df & 32 & 32 \\
Sig. &, 057 &, 200 \\
\hline
\end{tabular}

Pada kelas eksperimen yaitu kelas $\mathrm{IX}_{\mathrm{D}}$ yang menerapkan model pembelajaran Pair Check menunjukkan bahwa $\mathrm{df}=32$ dengan nilai signifikansi sebesar 0,057. Dalam hal ini, dapat disimpulkan bahwa nilai signifikansi kelas eksperimen dengan $\quad$ Sig $\geq 0,05$ maka data berdistribusi normal. Sedangkan, pada kelas kontrol yaitu kelas $\mathrm{IX}_{\mathrm{A}}$ yang menerapkan model pembelajaran konvensional menunjukkan bahwa $\mathrm{df}=32$ dengan nilai signifikansi sebesar 0,200. Dalam hal ini, dapat disimpulkan bahwa nilai signifikansi kelas kontrol dengan $\mathrm{Sig} \geq$ 0,05 maka data berdistribusi normal. Sehingga, dapat disimpulkan bahwa kelas eksperimen $\left(\mathrm{IX}_{\mathrm{D}}\right)$ yang menerapkan model pembelajaran Pair Check dan kelas kontrol $\left(\mathrm{IX}_{\mathrm{A}}\right)$ yang menerapkan model pembelajaran konvensional memiliki data yang berdistribusi normal.

Uji homogenitas dilakukan untuk melihat variansi data hasil belajar pada kedua kelas sampel homogen (mempunyai varians yang sama) atau tidak. Dalam penelitian ini, uji homogenitas variansi yang dilakukan dengan menggunakan bantuan program SPSS statistik 20.

Tabel 4.Rangkuman Uji Homogenitas Data Posttest

\begin{tabular}{lllrrr}
\hline NO & Kelas & Varians & $\mathbf{F}_{\text {Hitung }}$ & $\mathbf{F}_{\text {Tabel }}$ & Keterangan \\
\hline 1 & Eksperimen & 159,08 & \multirow{2}{*}{1,45} & 1,82 & Homogen \\
& Kontrol & 231,16 & & & \\
\hline
\end{tabular}

Dapat dilihat bahwa, varians kelas eksperimen yang menerapkan model pembelajaran Pair Check adalah 159,08 dan varians kelas kontrol adalah 231,16 sehingga $F_{\text {hitung }}=1,45$ dan diperoleh $\mathrm{F}_{\text {tabel }}$ dengan $\mathrm{FINV}(0.05,31,31)$ sebesar 1,82. Dalam hal ini, dapat disimpulkan bahwa 1,82 > 1,45 maka kedua varians homogen.

Tabel 5. Hasil Uji Hipotesis 1 dan 2

\begin{tabular}{crrrrrr}
\hline & \multicolumn{6}{c}{ Test Value $=75$} \\
\cline { 2 - 7 } Kelas & $\mathrm{T}$ & Df & $\begin{array}{c}\text { Sig. (2- } \\
\text { tailed) }\end{array}$ & $\begin{array}{c}\text { Mean } \\
\text { Difference }\end{array}$ & $\begin{array}{c}\text { 95\% Confidence Interval } \\
\text { of the Difference }\end{array}$ \\
\cline { 2 - 7 } & & & & & Lower & Upper \\
Eksperimen & 2,074 & 31 &, 046 & 4,625 &, 08 & 9,17 \\
Kontrol & $-1,279$ & 31 &, 210 & $-3,438$ & $-8,92$ & 2,04 \\
\hline
\end{tabular}

Untuk perhitungan uji hipotesis menggunakan uji t satu pihak (one sample t test) dengan bantuan SPSS for windows 20. Adapun hasil statistik kelas eksperimen menunjukkan bahwa nilai Sig.(2-tailed) $=0,046$, sesuai dengan Getut (2014: 85) untuk uji one sample t test hasil Sig. dibagi dengan 2 maka Sig. $=0,046 / 2=0,023$. Sehingga, 0,023 $<0,05$ maka model 
pembelajaran Pair Check efektif terhadap hasil belajar matematika siswa kelas IX SMP Negeri 17 Batam TP. 2018/2019. Adapun hasil statistik uji kelas kontrol menunjukkan bahwa nilai Sig. $(2$-tailed $)=0,210$, maka Sig. $=0,210 / 2=0,105$. Sehingga, 0,105 $\geq 0,05$ maka model pembelajaran konvensional tidak efektif terhadap hasil belajar matematika siswa kelas IX SMP Negeri 17 Batam TP. 2018/2019.

Untuk perhitungan uji hipotesis 3 menggunakan independent sample t-test dengan bantuan SPSS for windows 20. Adapun hasil uji hipotesis 3 adalah sebagai berikut diperoleh nilai signifikansi sebesar 0,039 sehingga Sig < 0,05 maka $\mathrm{H}_{\mathrm{o}}$ ditolak sedangkan $\mathrm{H}_{\mathrm{a}}$ diterima. Jika $\mathrm{H}_{\mathrm{a}}$ diterima maka dapat disimpulkan bahwa terdapat perbedaan keefektifan antara model pembelajaran Pair Check dengan model pembelajaran konvensional terhadap hasil belajar matematika siswa kelas IX SMP Negeri 17 Batam TP. 2018/2019.

Berdasarkan observasi dan pengamatan yang dilakukan pada kelas eksperimen dan kontrol dapat dilihat bahwa penggunaan model pembelajaran kooperatif tipe pair check lebih efektif dari model konvensional. Dimana model pembelajaran pair check menuntut siswa untuk saling berbagi dalam kemampuan kognitifnya sehingga terjadi saling tukar pendapat dan melatih agar siswa aktif dalam proses pembelajaran. Pada proses saling berbagi dalam kemampuan kognitifnya membuat siswa lain tidak sungkan bertanya dengan temannya yang lebih mengerti. Setiap siswa juga dituntut untuk memiliki tanggung jawab terhadap tugasnya masing-masing. Keefektifan model pair check dapat dilihat pada beberapa siswa kelas IX yang bisa mengerjakan salah satu soal sukar yang bisa dilihat pada Gambar 1 berikut:

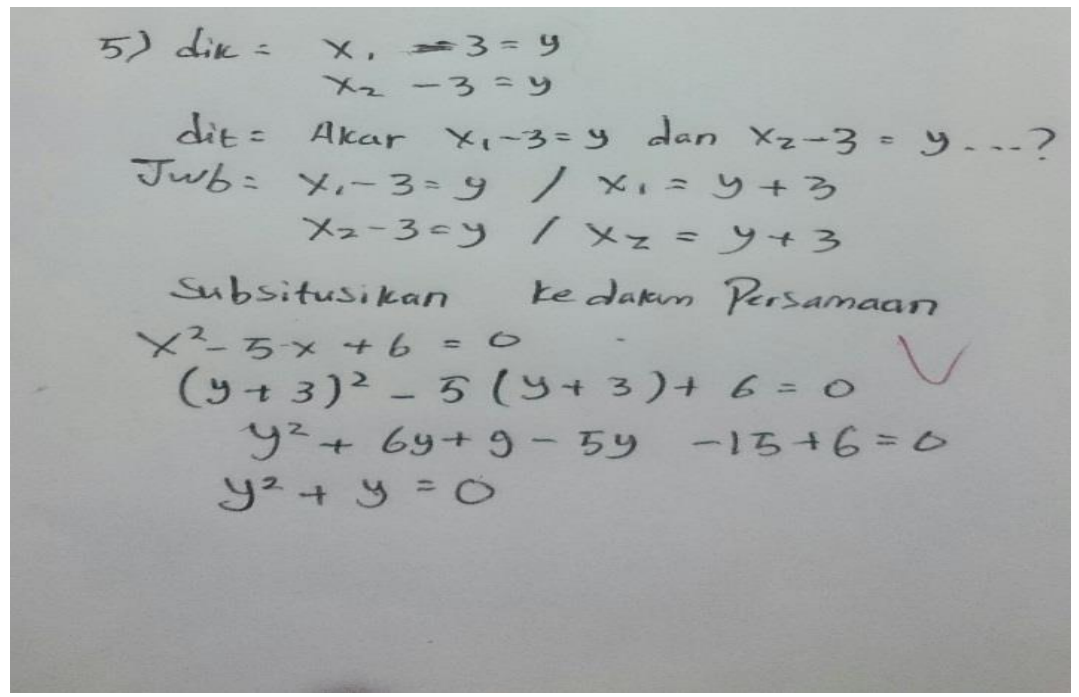

Gambar 1. Jawaban Siswa kelas Eksperimen

Untuk model pembelajaran konvensional Guru mendominasi pada proses pembelajaran dikelas. Siswa hanya duduk diam dan mendengarkan penjelasan guru sehingga kurang terjadinya interaksi antara siswa dan guru. Hanya siswa tertentu saja yang melakukan interaksi tanya jawab dengan guru, sedangkan siswa lain pasif dalam mengikuti pembelajaran. Sehingga menyebabkan model konvensional tidak efektif. Hal ini terlihat pada siswa kelas 
kontrol yaitu kelas $\mathrm{IX}_{\mathrm{A}}$ dimana tidak ada siswa yang bisa mengerjakan salah satu soal sukar yang bisa dilihat pada Gambar 2.

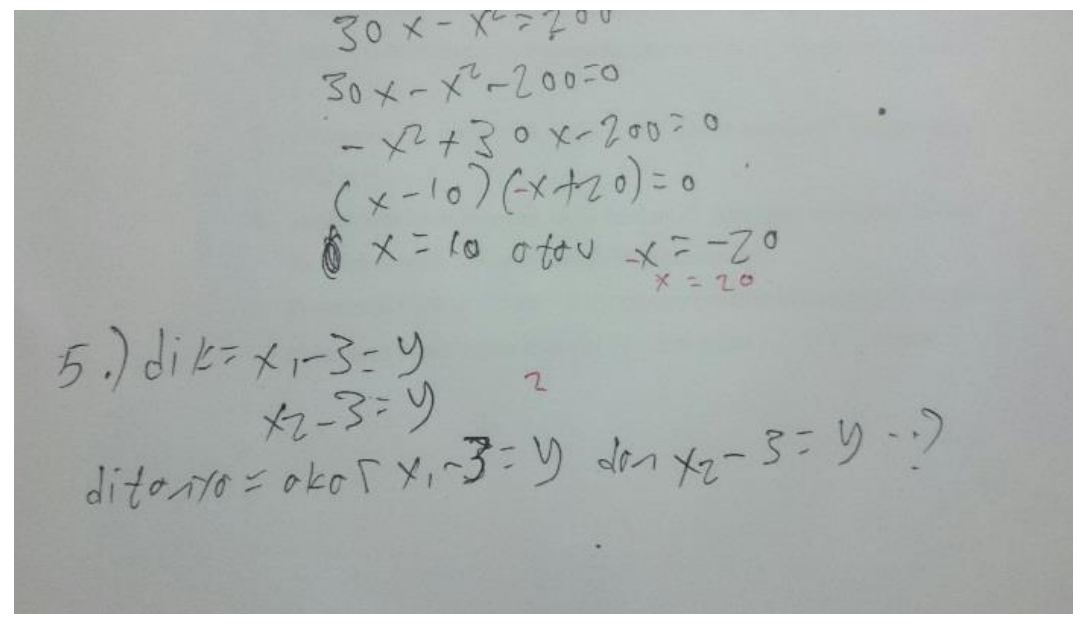

Gambar 2. Jawaban Siswa Kelas Kontrol

Dalam penelitian ini, siswa pada kelas eksperimen maupun kelas kontrol diajarkan dengan materi persamaan kuadrat, yang membedakan antara kelas ekperimen dan kelas kontrol adalah model yang diterapkan.Perlakuan yang diberikan pada kelas eksperimen dan kelas kontrol sangat jauh berbeda. Kelas eksperimen diberi perlakuan model pembelajaran Pair Check sedangkan pada kelas kontrol diberi perlakuan model konvensional.

Dari hasil penelitian diperoleh bahwa rata-rata hasil belajar metematika pada kelompok eksperimen yaitu 79,63 sedangkan pada kelompok kontrol nilai rata-ratanya 71,56. Hasil belajar matematika yang diterapkan model pembelajaran kooperatif tipe Pair Check lebih tinggi dari pada rata-rata hasil belajar matematika siswa yang diajarkan dengan menggunakan model pembelajaran konvensional.

Perolehan hasil belajar yang tinggi pada siswa yang dibelajarkan dengan model pembelajaran kooperatif tipe Pair Check diperkuat juga oleh pendapat Sanjaya dalam Yantiani et al (2013) yang menyebutkan beberapa kelebihan model pembelajaran kooperatif tipe pair check, antara lain dapat meningkatkan kemandirian siswa, meningkatkan partisipasi siswa untuk menyumbangkan pemikiran karena merasa leluasa dalam mengungkapkan pendapatnya, membentuk kelompok lebih mudah dan cepat, dan melatih kecepatan berpikir siswa. Pada siswa yang dibelajarkan dengan pembelajaran konvensional. Pada proses pembelajarannya, guru memberikan ceramah yang diselingi tanya jawab, serta pemberian evaluasi (Yulia \& Jamailah, 2016:163). Pada pembelajaran konvensional, siswa kurang mempunyai kesempatan untuk mengembangkan pengetahuannya, mengajukan masalah, maupun memecahkan masalah. Peran tutor sebaya juga sangat kurang, sehingga dalam pembelajaran konvensional sangat minim interaksi, terutama interaksi antar siswa.

\section{Kesimpulan dan Saran}

Berdasarkan hasil penelitian yang didapat, maka dapat ditarik kesimpulan:

1. Model pembelajaran Pair Check efektif terhadap hasil belajar matematika siswa kelas IX SMP Negeri 17 Batam TP. 2018/2019. 
2. Model pembelajaran konvensional tidak efektif terhadap hasil belajar matematika siswa kelas IX SMP Negeri 17 Batam TP. 2018/2019.

3. Terdapat perbedaan keefektifan antara model pembelajaran Pair Check dengan model pembelajaran konvensional terhadap hasil belajar matematika siswa kelas IX SMP Negeri 17 Batam TP. 2018/2019.

Berdasarkan hasil penelitian, peneliti ingin memberikan beberapa saran untuk perbaikan dan proses peningkatan pembelajaran matematika. Untuk itu diberikan beberapa saran sebagai berikut:

1. Bagi Guru diharapkan dapat menjadi altenatif untuk mengaktifkan siswa yang tidak aktif dan dapat meningkatkan hasil belajar dengan mengguakan model pembelajaran kooperatif tipe pair check.

2. Bagi Siswa, dapat membuat suasana belajar tidak monoton terutama pada mata pelajaran matematika sehingga siswa dapat aktif dalam kegiatan pembelajaran.

\section{Daftar Pustaka}

Hadi, S \& Kasum, M.U.(2015). Pemahaman Konsep Matematika Siswa SMP Melalui Penerapan Model Pembelajaran Kooperatif Tipe Memeriksa Berpasangan (Pair Checks). EDU-MAT Jurnal Pendidikan Matematika, 3(1), 59-66

Hendiana, H \& Soemarmo, U. (2014). Penilaian Pembelajaran Matematika. Bandung: Refika Aditama.

Istarani \& Ridwan,M. (2015). 50 Tipe, Strategi dan Teknik Pembelajaran Kooperatif. Medan : Media Persada

Kurniasih, I \& Sani, B. (2015). Ragam Model Pembelajaran. Bandung: Kata Pena.

Lestari, R \& Linuwih, S. (2012). Penerapan Model Pembelajaran Kooperatif Tipe Pair Checks Pemecahan Masalah Untuk Meningkatkan Social Skill Siswa. Jurnal Pendidikan Fisika Indonesia, 8, 190-194

Lubis, S. (2013). Metodologi Penelitian Pendidikan. Padang: Sukabina Press.

Huda, M. 2014. Cooperatve Learning. Yogyakarta: Pustaka Belajar

Sukarsa, D \& Arini. (2014). Penerapan Model Pembelajaran Kuantum Berbantuan Media Microsoft Power Point untuk Meningkatkan Aktivitas dan Hasil Belajar IPA Siswa Kelas IV Semester 1 SD Negeri 6 Menanga. MIMBAR PGSD Undiskha, 2(1).

Yantiani,N.M et al (2013). Pembelajaran Kooperatif Pair Check Berpengaruh Terhadap Hasil Belajar Materi Bangun Ruang Dan Bangun Datar Siswa Kelas IV Gugus IV Semarapura. MIMBAR PGSD Undiksha

Yulia, P \& Jamailah, S (2016). Efektifitas Pembelajaran Matematika Melalui PMRITerhadap Hasil Belajar Matematika Siswa Kelas VIII. PYTHAGORAS, 5(2): 158-164. 